\title{
Agências reguladoras e transparência: a disponibilização de informações pela Aneel*
}

Otávio Prado**

S u MÁRio: 1. Introdução; 2. A Agência Nacional de Energia Elétrica (Aneel); 3. Análise da transparência da Aneel; 4. Conclusões e considerações finais.

SumMARY: 1. Introduction; 2. The Brazilian Electricity Regulatory Agency (Aneel); 3. Analyzing Aneel's transparency; 4. Conclusions and final remarks.

PAlavras-CHAVE: agências reguladoras; transparência; accountability; disponibilização de informações; websites.

KEY WORDS: regulatory agencies; transparency; accountability; information availability; websites.

Este artigo analisa os mecanismos de transparência da Agência Nacional de Energia Elétrica (Aneel), por meio da avaliação da disponibilidade de informações em seu website. Verifica-se a atuação da agência na promoção da transparência do setor e também de seus próprios atos, pelo cumprimento do disposto em seu contrato de gestão e da disponibilização de documentos e informações sobre o setor de energia elétrica. Por causa do enfoque na transparência, neste artigo não serão feitas considerações sobre a atuação da agência como reguladora do setor. A escolha da Aneel como objeto empírico do trabalho deve-se ao fato dela ser uma das primeiras agências reguladoras independentes criadas no Brasil, permitindo não só uma análise temporal de maior alcance, mas também a obtenção de uma série maior de documentos e informações sobre sua atuação.

* Artigo recebido em fev. e aceito em maio 2006.

** Geólogo e historiador, mestre e doutorando em administração pública e governo pela Eaesp/ FGV. Funcionário público municipal (PMSP) e pesquisador do Programa Gestão Pública e Cidadania da Eaesp/FGV. Endereço: Av. 9 de Julho, 2029, 11ํandar - Bela Vista - CEP 01313902, São Paulo, SP, Brasil. E-mail: otavioprado@fgvsp.br. 


\section{Regulatory agencies and transparency: information availability from Aneel}

This article analyzes the transparency mechanisms of the Brazilian Electricity Regulatory Agency (Aneel), assessing the information available at its website. One can see that the agency has promoted the sector's transparency as well as that of its own activities, by complying with the clauses of its management contract and by publishing documents and information about the electricity sector. Due to its focus on transparency, this article will not discuss the agency's regulatory activities. Aneel was chosen as the empirical object of this article because it is one of the first independent regulatory agencies in Brazil, allowing not only a broader temporal analysis, but also a larger mass of documentation and information on its activities.

\section{Introdução}

As discussões sobre reforma do Estado emergem nos países capitalistas a partir da década de 1980, procurando responder à grande crise do Estado intervencionista de tipo keynesiano e aos modelos de welfare state construídos no pós-guerra. Se os primeiros sintomas dessa crise surgem nos anos 1970 e 1980, com a recessão econômica, com os enormes déficits fiscais e com o conseqüente questionamento das despesas públicas, em particular as do welfare state, eles se agudizam com a globalização e as mudanças tecnológicas dos anos 1990 (Abrucio, 1998).

Inicialmente, as reformas visavam diminuir o tamanho do aparato estatal e os gastos públicos, resultando na reestruturação do modo de intervenção e gestão do aparelho estatal. Além de medidas cada vez mais rígidas de controle dos gastos, essa primeira geração de reformas teve como resultados principais privatizações, concessões e estabelecimento de parcerias entre governo e iniciativa privada e, ainda, a redefinição do papel do Estado, que passa de executor para indutor e regulador das atividades econômicas (Rezende, 2002). Já uma segunda geração de reformas centrou a discussão na necessidade de maior eficiência na gestão dos recursos públicos e na demanda de maior participação da sociedade na gestão e na supervisão dos serviços públicos.

Segundo Pó e Abrucio (2004), um dos resultados desse processo no Brasil foi a criação das agências reguladoras. Durante a primeira geração de reformas foram criadas as agências reguladoras relacionadas à privatização e quebra do monopólio do Estado nos setores de infra-estrutura, casos da Agência Nacional de Energia Elétrica (Aneel), Agência Nacional de Telecomunicações (Anatel) e Agência Nacional de Petróleo (ANP). À época, uma das justificativas para a criação das agências foi a necessidade de eliminar as falhas de mercado, 
baseando-se na teoria de que, sob determinadas condições, mercados competitivos poderiam levar a uma alocação ideal de recursos, segundo os termos de Pareto. Por essa justificativa, a regulação poderia minimizar as falhas a um custo razoável, melhorar a eficiência do mercado ou então assegurar sua viabilidade, onde a confiança, a transparência e a clareza de informações são de extrema importância (Majone, 1999).

Essa primeira geração de agências reguladoras, criadas a partir de 1996 no contexto das privatizações e quebra do monopólio estatal e inspiradas pela experiência internacional, foram configuradas como entes públicos dotados de independência em relação ao Poder Executivo. Na sua criação foi importante a atuação do Congresso, bem como as recomendações elaboradas pelo Conselho da Reforma do Estado, órgão consultivo ligado ao presidente da República, embora com menor participação do Ministério da Administração Federal e Reforma do Estado $\left(\mathrm{Mare}^{1}\right.$ ) (Pacheco, 2004). O formato institucional foi pensado de forma a garantir a credibilidade regulatória, principalmente do ponto de vista econômico, já que o governo, ao procurar obter recursos para pagamento da dívida pública, argumentava não poder investir nesses setores.

Outra característica apontada por Pó e Abrucio (2004) foi a falta de um modelo comum nos processos decisórios criadores dessas agências, com grande influência do histórico de cada setor na conformação das estruturas regulatórias. Os autores advertem que essa característica implica o risco da grande especialização levar ao insulamento da agência, dificultando sua avaliação por atores com menor conhecimento da área, ao mesmo tempo em que pode favorecer sua captura por grupos de interesse mais vinculados às áreas. Por isso, a existência de mecanismos de accountability nas agências reguladoras autônomas é fundamental para garantir o desempenho de suas funções e o escrutínio público delas.

Associando o tema da regulação com a necessidade de transparência, mais recentemente surgem debates sobre a acessibilidade das informações públicas e, conseqüentemente, a melhor prestação de contas dos governantes à sociedade. Essas discussões colocaram claramente o tema da accountability democrática na agenda da reforma, tanto como meio de melhorar o controle e a participação nas políticas públicas, mas também como forma de legitimação do próprio governo (Clad, 2001). Embora o tema da accountability tenha sido freqüente no debate internacional dos últimos anos, o termo não está

\footnotetext{
${ }^{1}$ Ver mais em: Brasil (1995).
} 
precisamente definido, nem tampouco há uma tradução precisa dessa expressão na língua portuguesa. A OCDE, em suas publicações, utiliza uma definição normativa de accountability como a obrigação de demonstrar que determinada ação está sendo conduzida de acordo com as regras e padrões acordados, ou que seus resultados estejam sendo reportados honesta e apuradamente pelos programas ou ao longo dos mandatos (OCDE, 2002). Nos textos divulgados pela ONU, o termo accountability é definido, para línguas nãoinglesas, como relacionado ao agir com responsabilidade e de forma responsiva, ao mesmo tempo. Przeworski, Stokes e Manin (1999) associam accountability ao conceito de representação. Para eles, um governo é accountable se os cidadãos podem discernir entre governos representativos e não-representativos e aplicar sanções apropriadas, mantendo os bons governantes e destituindo os demais. Dessa forma, o mecanismo de accountability atuaria desde os resultados das ações dos governantes até a fase de aplicação de sanções pelos cidadãos, sendo as eleições apenas um desses mecanismos de punição (Przeworski, Stokes e Manin, 1999). Além de O’Donnell (1998), que diferenciou no conceito de accountability dimensões verticais (dos governantes diretamente ao povo através do processo eleitoral, controle da mídia etc.) e horizontais (controles recíprocos entre poderes ou mecanismos institucionais de checks and balances), Stark e Bruszt (1998) contribuíram para discussão com o conceito de responsabilidade política estendida ao longo de todo o mandato, e não apenas no processo eleitoral, envolvendo uma pluralidade de atores dentro do Estado e na sociedade.

Sintetizando essas considerações, pode-se entender accountability democrática como um princípio que se expressa em mecanismos institucionais que devem constranger os governos continuamente a prestar contas à sociedade e a outros atores no sistema político (Legislativo, Judiciário etc.). Para a sua plena realização, tais mecanismos institucionais devem garantir o controle público das ações dos governantes, permitindo aos cidadãos não só ser informados sobre aquelas ações, mas também possibilitando-lhes influir na definição das metas coletivas, não somente com as eleições, mas ao longo dos mandatos dos seus representantes, garantindo a responsabilização ininterrupta dos governos. Em suma, accountability é um processo democrático amplo que contém distintas etapas: informação correta e transparente aos cidadãos; prestação de contas dos governantes e sua responsabilização no sentido estrito, isto é, envolvendo a aplicação de recompensas aos governantes (por exemplo, reeleição) ou punições a eles quando seus atos forem desaprovados ou rejeitados (por exemplo, derrotas eleitorais, impeachment etc.). Dessa forma, podemos assumir que a transparência seria uma das condições fundamentais, embora não suficiente, para a accountability dos governos. 
A seguir, apresentamos algumas breves considerações sobre a criação da Aneel, de forma a fundamentar a análise da transparência da Aneel e a publicação de informações em seu website.

\section{A Agência Nacional de Energia Elétrica (Aneel)}

O projeto de criação da Aneel foi enviado pelo Executivo federal ao Congresso Nacional no final de 1995, em um momento posterior às primeiras privatizações no setor, causando alguns problemas de legitimidade, principalmente quanto à arbitragem de controvérsias (Salgado, 2003). O projeto inicial seguia o modelo de autarquia convencional, sem previsão de autonomia decisória nem os demais requisitos de estrutura e procedimentos que caracterizariam as agências reguladoras. Coube ao Congresso a iniciativa de questionamento do modelo tradicional e a busca de modelos alternativos, a partir da experiência internacional. Dessa forma, apesar da iniciativa de criação ter sido do Poder Executivo, coube ao Poder Legislativo trazer para a agenda a discussão do grau de autonomia desejável para os novos entes reguladores (Pacheco, 2004).

A Aneel foi criada pela Lei $\mathrm{n}$ - 9.427, de 26 de dezembro de 1996, e regulamentada pelo Decreto no 2.335, de 6 de outubro de 1997, que aprovou sua estrutura regimental. O contrato de gestão da Aneel teve sua primeira versão aprovada em 1998 e o Plano de Metas aprovado em $1999 .^{2}$ A agência, configurada como uma autarquia sob regime especial e vinculada ao Ministério das Minas e Energia (MME), tem como objetivo regular e fiscalizar a produção, transmissão e comercialização de energia elétrica, em conformidade com as políticas e diretrizes do governo federal. A Aneel possui autonomia gerencial e financeira e competência para normatizar questões técnicas, assim como autonomia decisória, garantida pelos mandatos fixos de sua diretoria, cuja conformação foi pensada de forma a garantir qualidade técnica e neutralidade em suas decisões. Quanto a isso, Salgado (2003) adverte que o fato de a maior parte dos dirigentes da Aneel ter sido formada a partir dos antigos quadros do Departamento Nacional de Águas e Energia Elétrica (DNAEE), poderia sinalizar aos investidores que a regulação do setor enfatiza questões técnicas e operacionais, e não a criação de incentivos econômicos para a formação de um mercado verdadeiramente competitivo.

\footnotetext{
${ }^{2}$ Ambos têm sido renovados anualmente.
} 
As demais entidades que formam o desenho institucional do setor energético do país são o Mercado Atacadista de Energia (MAE), criado pela Lei $\mathrm{n}^{\underline{0}}$

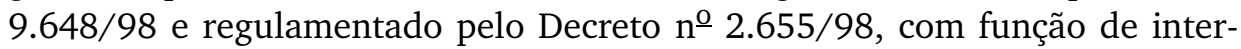
mediar as transações de compra e venda de energia elétrica, e o Operador Nacional do Sistema Elétrico (ONS), entidade privada formada por diversos agentes do setor, consumidores e poder concedente, com função de programar o despacho de energia, a partir das disponibilidades declaradas pelas geradoras. Ao mesmo tempo, Furnas, Chesf e Eletronorte permanecem estatais, assim como as redes de transmissão, resultando em um quadro complexo e potencialmente gerador de conflitos no mercado de geração e transmissão de energia elétrica. Além disso, o baixo grau de coordenação entre a Aneel, a Agência Nacional de Águas (ANA) e a Agência Nacional do Petróleo (ANP), dificulta a regulação da indústria de gás e o uso das águas (Salgado, 2003).

Todos esses fatores podem influir no grau de transparência da agência, principalmente se considerarmos a sua necessidade de legitimação. A seção seguinte apresenta a avaliação empírica da transparência da Aneel, a partir da análise da publicação de informações em seu website.

\section{Análise da transparência da Aneel}

A metodologia de análise da transparência da Aneel empregada neste artigo não associa automaticamente transparência de informações à prestação de contas e accountability pela agência, mas relaciona transparência apenas à disponibilização de informações. Além disso, considera-se que para uma efetiva transparência não basta apenas que as informações estejam disponíveis, mas que tenham consistência e inteligibilidade, estando "decodificadas" em linguagem acessível para entendimento do público em geral (Sartori, 2001).

Inicialmente, procurou-se verificar a existência de mecanismos institucionais de transparência a partir da própria legislação que criou a agência. Em sua lei de criação, a referência à necessidade de transparência da Aneel aparece de forma muito vaga. No contrato de gestão, ainda que de forma pouco explícita, temos que a agência deve "promover a educação e informação dos agentes e demais envolvidos sobre as políticas, diretrizes e regulamentos do setor de energia elétrica" e "promover a transparência e efetividade nas relações com a sociedade". ${ }^{3}$

\footnotetext{
3 Trechos extraídos do contrato de gestão da Aneel, cláusula 2ª , parágrafos 7 e 9 . Acessível em: $<$ www.aneel.gov.br/5.htm >. 
Tendo em vista que a necessidade de transparência da Aneel não aparece de forma nítida em sua legislação, procurou-se obter dados e informações sobre a prestação de contas da agência e sobre sua atuação na regulação do setor. Para obter um parâmetro de comparação com um órgão da administração direta, o website da Aneel foi comparado com o do Ministério de Minas e Energia (MME), ao qual a agência está vinculada, apenas do ponto de vista da publicação de informações. Finalmente, os dados obtidos foram avaliados em termos do conteúdo apresentado, adequação à legislação de contas públicas (Brasil, 1998, 1999) e inteligibilidade/decodificação das informações.

\section{Análise do website}

O website da Aneel é relativamente bem estruturado e de fácil visualização e os principais itens podem ser localizados a partir dos menus de sua página principal. Algumas informações encontram-se dispersas, mas não é difícil localizá-las. A grande maioria do material informativo é disponibilizado em arquivos para download. Nos casos em que existe a necessidade de uso de software adicional para leitura dessas informações, ele é fornecido em um link no próprio website. Além disso, a página principal exibe um mecanismo de busca eficiente que permite encontrar a informação desejada por todo o conteúdo do website, assim como um mapa do site que permite a localização dos links e menus.

Assim como o website do MME, a Aneel apresenta sua estrutura organizacional, indicando não só o organograma, mas também informando os nomes dos ocupantes dos principais cargos, suas atribuições e uma forma de contato. Além disso, toda a legislação de criação da agência e legislação complementar correspondente estão disponíveis.

Em relação à avaliação do conteúdo, subdividimos os tipos de informações em três grupos distintos: o primeiro corresponde às informações relativas à atuação da agência, o segundo corresponde às informações do setor elétrico e o terceiro, à prestação de contas da própria Aneel.

\section{Primeiro grupo — informações sobre a atuação da agência}

Neste grupo temos os dados sobre as audiências públicas, consultas públicas, contratos de concessão, fiscalização econômica e financeira, processos administrativos, licitações e revisões tarifárias. 
As audiências públicas são instauradas pela Aneel sempre que um assunto implique alterações ou ajustes na legislação da agência, ou interfira diretamente nos interesses da sociedade e dos agentes do setor elétrico. Por isso, as informações sobre as audiências públicas, parte do seu processo decisório, são consideradas pela própria agência fatores importantes para a transparência de suas ações. Na avaliação pudemos verificar que o material sobre as audiências é amplamente disponibilizado pela agência, sob a forma de arquivos para download. As contribuições individuais ou de grupos podem ser enviadas pelo próprio website, sendo depois também disponibilizadas para download.

As consultas públicas são criadas pela Aneel para recebimento de sugestões e comentários para as propostas de resoluções e ações em andamento. Na pesquisa pudemos verificar que, assim como no caso das audiências públicas, o material das consultas é amplamente disponibilizado no website. Também existe a possibilidade do envio de contribuições diretamente pelo website.

Os contratos de concessão são os contratos assinados entre a Aneel e as empresas prestadoras dos serviços de transmissão e distribuição de energia. Esses contratos estabelecem as regras sobre tarifa, regularidade, continuidade, segurança, atualidade e qualidade dos serviços e do atendimento prestado aos consumidores. As concessões do sistema de transmissão são firmadas em contrato com duração de 30 anos. Os contratos de concessão de geração, outorgados a partir de processos licitatórios, têm vigência de 35 anos. Esses contratos podem ser renovados por igual período, a critério da Aneel. As concessões outorgadas anteriormente às leis $\mathrm{n}^{\mathrm{O}}$ 8.987/95 e $\mathrm{n}^{\mathrm{O}}$ 9.074/95 têm renovação por 20 anos. Na análise do website pudemos verificar que são apresentados não só a íntegra dos contratos de geração, transmissão e distribuição, mas também os termos aditivos e eventuais termos de ajuste de conduta.

Em relação às suas atividades de fiscalização econômica e financeira, a Aneel é responsável por averiguar a gestão dos agentes e preservar o equilíbrio econômico e financeiro das concessões, de forma a garantir a modicidade das tarifas. Essas atividades são subdivididas em três enfoques.

- anuências correspondem às transações realizadas pelos agentes que necessitam de anuência da Aneel;

- acompanhamento do desempenho dos agentes - a partir do fluxo de informações recebidas dos diversos agentes, a Aneel avalia o desempenho, o cumprimento das obrigações contratuais e da regulamentação setorial, bem como da legislação vigente; 
- visitas de fiscalização correspondem às fiscalizações in loco da Aneel, para verificar os procedimentos adotados pelos agentes e validação dos dados e informações prestados pelas empresas como subsídio aos processos decisórios da Aneel, em especial os referentes às revisões tarifárias.

Na avaliação pudemos constatar que estão disponíveis os relatórios e demais informações enviadas pelas empresas à Aneel, em arquivos para download. Apesar de alguns relatórios possuírem um conteúdo essencialmente técnico, é possível a uma pessoa com conhecimento básico de finanças compreender as informações apresentadas.

Em relação aos processos administrativos, a Aneel disponibiliza um sistema online de consulta dos processos em tramitação na agência, assim como as normas organizacionais que disciplinam os procedimentos internos relacionados aos processos administrativos e a pauta e ata das reuniões públicas que envolvam interesses dos agentes do setor elétrico e dos consumidores. A análise mostrou que o website da Aneel permite a consulta a todo este material, inclusive os relativos às reuniões públicas da diretoria. As pautas e os relatórios dos processos também estão disponíveis. Em geral esses documentos são resumidos, mas permitem conhecer os temas tratados.

Em relação às informações sobre as licitações, o website da Aneel apresenta para download os editais de licitações de geração e transmissão, as licitações administrativas, os programas de geração e transmissão, assim como os resultados finais das licitações. O website da Aneel apresenta também informações relativas à revisão tarifária e informações técnicas sobre os processos de revisão e reajuste, com os respectivos documentos e decisões da Aneel.

Como síntese das observações desse grupo, podemos perceber que a disponibilização de informações é bem grande por parte da agência. O material disponibilizado cobre todas as informações necessárias para o acompanhamento da atuação da agência. Mesmo quando as informações têm um caráter mais técnico, é possível entender seu conteúdo, desde que a pessoa tenha conhecimentos mínimos sobre o tipo de informação apresentada. Em comparação com os mesmos tipos de informação disponíveis no website do MME, o website da Aneel possui muito mais conteúdo disponível, indicando que, pelo menos nesse aspecto, sua transparência é maior que a da administração direta.

\section{Segundo grupo — informações do setor elétrico}

Neste grupo temos a avaliação da disponibilização de informações sobre o setor elétrico, incluindo a do website da Aneel, das informações repassadas pelas empresas reguladas. 
No website da Aneel encontramos um banco de dados online sobre o parque gerador de energia elétrica brasileiro, denominado Banco de Informações de Geração (BIG). A Aneel indica que os objetivos do banco são a promoção da universalização e uniformização de informações sobre o setor elétrico, dando pleno conhecimento aos agentes do mercado, investidores estrangeiros e nacionais, autoridades governamentais, bem como a sociedade em geral, sobre a geração de energia elétrica no Brasil. Verificamos que são apresentadas informações sobre as usinas regularizadas em operação e em construção, assim como as outorgadas no período de 1998 a 2005 (englobando hidrelétricas, pequenas centrais hidrelétricas, termelétricas, nucleares, eólicas e outras fontes alternativas). As informações são fornecidas em três módulos de consulta: capacidade de geração do Brasil, resumo estadual e agente de geração. As informações são bem completas e permitem obter um amplo panorama do setor de energia elétrica no Brasil.

Uma outra seção do website exibe informações complementares do setor elétrico, relativas às autorizações e registros, cadastro dos agentes, compensação financeira, conselhos de consumidores de energia elétrica, contratos de concessão, gestão e estudos hidroenergéticos, mercado de distribuição, monitoramento hidrológico das usinas, responsabilidade social e tensões secundárias. Complementando essas informações do setor elétrico, existem informações disponíveis sobre co-geração, conta consumo de combustíveis, fontes renováveis, hidrelétricas, horário de verão, importação de energia, linhas de transmissão, pequenas centrais hidrelétricas, potenciais hidráulicos e termelétricas. A análise dessas informações, também disponíveis em versão para download, mostra que a agência procura disponibilizar o maior volume possível de informações repassadas pelas empresas reguladas, além de dados adicionais sobre o setor elétrico. Apesar de grande parte das informações estar em linguagem técnica, é possível a uma pessoa com um mínimo de conhecimento da área entender a linguagem dos relatórios.

Em relação à legislação aplicável ao setor, a Aneel permite o download não só da legislação básica, mas também das normas de organização e das resoluções normativas. Para isso, existe um eficiente mecanismo de pesquisa legislativa, que busca o material emitido e publicado pela Aneel no Diário Oficial da União e em outros bancos de dados externos ao website. Como fator distintivo temos um glossário contendo os principais termos empregados na legislação e também no setor elétrico.

Finalmente, a avaliação indicou que parece existir uma recente preocupação da agência com a produção de material educativo. Foi criada em 2005 uma seção do website em que é possível acessar e fazer o download de seis publicações de cunho educativo, denominadas cadernos temáticos. Essas publica- 
ções possuem linguagem acessível a uma ampla parcela da população e tratam de temas de interesse mais imediato do que os relatórios técnicos citados. Os títulos disponíveis até o momento são: Descentralização de atividades; Compensação financeira pela utilização de recursos hídricos para geração de energia elétrica; Energia assegurada; Tarifas de fornecimento de energia elétrica; Acesso e uso dos sistemas de transmissão e de distribuição; e Desafios da regulação do setor elétrico, modicidade tarifária e atração de investimentos.

\section{Terceiro grupo - prestação de contas}

Neste grupo temos as informações relativas à prestação de contas da Aneel. Entre as informações analisadas temos os dados da ouvidoria, as prestações de contas públicas e a prestação de contas relativas ao contrato de gestão.

Segundo a Aneel, a ouvidoria deve ser distinta das centrais de teleatendimento das empresas reguladas, que funcionariam como um primeiro filtro para as solicitações daqueles com quem elas mantêm relação comercial ou institucional. A ouvidoria utilizaria as informações desses serviços como subsídio para corrigir deficiências no atendimento. Dessa forma, ela deveria ser acionada diretamente apenas se o cliente estivesse insatisfeito com a solução que lhe foi apresentada pelo serviço específico de atendimento das empresas. Suas funções principais seriam a identificação de lacunas na regulação; aperfeiçoamento da regulação existente; subsídio à ação de fiscalização da agência; melhoria do relacionamento cliente/concessionária; correção dos procedimentos internos do setor; aprimoramento da prestação do serviço da concessionária e solução dos questionamentos apresentados. O website da Aneel informa também que as atividades da ouvidoria foram descentralizadas em 13 estados, sendo que, em sete, o atendimento ainda é feito pela Aneel.

A avaliação mostrou que, quanto à atividade das ouvidorias descentralizadas, a Aneel se limita a informar os seus endereços eletrônicos. Quanto à prestação de contas da atuação da sua ouvidoria, encontramos apenas um relatório sintético, denominado Índice de Qualidade de Atendimento, com dados referentes a 2001. Esse relatório foi elaborado por uma consultoria da Universidade Federal do Paraná e realizado pelo Instituto Vox Populi por meio de entrevistas. O relatório resultante apresenta apenas dados estatísticos de atendimento, sem menção a processos de auditoria internos da agência. Conclui-se pelo material disponibilizado que das funções principais da ouvidoria, definidas pela própria Aneel, apenas a correção de deficiências quanto às solicitações de atendimento das empresas reguladas parece estar sendo cumprida. 
Quanto à prestação de contas públicas, a Lei Federal de Contas Públicas (Lei no 9.755 de 16 de dezembro de 1998) determina que todos os entes da administração direta e indireta devem obrigatoriamente publicar sua prestação de contas públicas, inclusive pela internet, apresentando demonstrativos anuais. Esses demonstrativos são referentes aos balanços orçamentários; compras; contratos e seus aditivos; demonstrativos de receitas e despesas; execução dos orçamentos; orçamentos anuais; recursos repassados e tributos arrecadados.

No website da Aneel encontramos apenas os demonstrativos de 2001. Uma das hipóteses possíveis para esse descumprimento à lei, comum também na maior parte dos órgãos da administração direta, decorre do aviso colocado pelo Tribunal de Contas da União em seu website informando que: "Alertamos aos entes federados que, por parte do Tribunal de Contas da União, não foram estabelecidas punições relativas ao descumprimento da IN TCU no $28 / 99 " .4$

Em relação à prestação de contas do contrato de gestão firmado entre a Aneel e o MME, o website apresenta os relatórios anuais de prestação de contas. Os relatórios são eminentemente técnicos e voltados a questões operacionais, especialmente quanto ao cumprimento do plano de metas. São considerados alguns aspectos sobre as medidas internas para saneamento das deficiências encontradas na atuação da agência. Apesar disso, não estão relacionadas com uma atividade de auditoria interna, sendo apenas justificativas pelo não-cumprimento das metas acordadas nos contratos.

Finalmente, apesar de não diretamente relacionadas à transparência, mas sim à participação e controle social na agência, duas iniciativas da Aneel podem ser acessadas em seu website: o fórum virtual e os conselhos de consumidores.

O fórum virtual, denominado Forte integração - fórum técnico de integração da Aneel e sociedade - é um fórum eletrônico criado para o debate sobre o setor energético do país. Seus objetivos, explicitados pela agência, são a promoção da integração técnica dos agentes públicos e privados do país, envolvidos no setor energético, a disseminação do conhecimento e o debate de temas de interesse do setor energético do país, de forma a estimular a integração de idéias e a convergência de objetivos no setor energético e o aprimoramento da massa crítica de técnicos envolvidos com as questões energéticas do país. A análise do conteúdo e da participação no fórum mostrou que nos

${ }^{4}$ Ver em <www.contaspublicas.gov.br/>. 
últimos 12 meses foram enviadas ao fórum cerca de 100 mensagens, sendo que uma parte considerável dessas mensagens se refere à indicação de textos para leitura e debate e informações sobre eventos de interesse do setor, enviados pelos administradores do fórum ou por membros do corpo técnico da própria Aneel, indicando que o fórum não é muito ativo. O tema mais freqüentado, entre os tópicos ativos, é sobre desenvolvimento sustentável no setor energético brasileiro, com 25 mensagens até o momento.

Os conselhos dos consumidores, previstos inicialmente no art. 13 da Lei no 8.631 de 1993, foram regulamentados pela Resolução Aneel no 138/2000. Essa resolução diz que a atribuição de organização dos conselhos é das empresas de energia. Esses conselhos são formados por dois conselheiros (titular e suplente) para cada categoria de consumo: residencial, comercial, industrial, rural e poder público. Uma vaga também é prevista para um representante das instituições de defesa do consumidor, que pode ser indicado pelo Ministério Público ou pelos Procons. A função dos conselhos é acompanhar as ações de fiscalização e o atendimento às reclamações dos usuários. Para isso eles devem elaborar um plano anual de atividades, sendo-lhes facultada a apresentação de projetos especiais para uso das receitas derivadas de multas em benefícios ao consumidor. No website da Aneel existe uma página com links para todos os conselhos criados e também um modelo para a elaboração do plano de metas. Existe também um link para material institucional do Código de Defesa do Consumidor e alguns vídeos institucionais.

\section{Conclusões e considerações finais}

Como conclusão da análise da transparência, pudemos constatar alguns pontos importantes para a definição da transparência da Aneel. Em relação à estruturação do website, que se relaciona com a transparência na medida em que facilita ou dificulta o acesso às informações, a pesquisa constatou que sua organização é um pouco confusa, embora em menor grau que outras agências e órgãos da administração direta. Essa falta de padrão comum é um dos obstáculos ao desenvolvimento do governo eletrônico no Brasil, reconhecido pelo próprio governo federal em sua política de governo eletrônico (Brasil, 2002). A distância em termos de estruturação e tecnologia dos websites governamentais em relação aos sites comerciais ainda é muito grande. O governo federal reconhece que os custos envolvidos não são os maiores impeditivos para a melhoria na acessibilidade às informações em websites governamentais. A limitação maior é mesmo quanto à necessidade de reestruturação interna dos órgãos e a otimização dos processos internos do governo. 
Considerando apenas o material disponibilizado pela Aneel sobre sua atuação e sobre o setor elétrico, podemos classificar sua transparência como muito boa. Em comparação com o material disponibilizado pelo website do MME, o website da Aneel possui sensivelmente mais informações. Mesmo as informações repassadas pelas empresas reguladas estão disponibilizadas no site da Aneel, que tem o mérito de servir como depositário de informações e atuar como um verdadeiro portal do setor de energia elétrica, fornecendo links para as empresas que atuam no setor e apresentando uma grande série de informações e dados, alguns em tempo real. Pode-se perceber na pesquisa que o material disponibilizado, em sua maior parte, é de boa qualidade. Mesmo aqueles de caráter mais técnico permitem seu entendimento por um cidadão comum. A preocupação recente da Aneel com a produção de material didático à população, para a disseminação de informações do setor, é uma iniciativa importante para a transparência.

As informações sobre a prestação de contas da agência são mais escassas. Mesmo aquelas que obrigatoriamente devem ser disponibilizadas, como as tratadas na Lei de Contas Públicas, estão desatualizadas. Essa deficiência não é exclusividade da Aneel e deve-se, provavelmente, à ausência de mecanismos de punição mais efetivos quanto ao cumprimento da lei. Outra constatação da pesquisa é que a ouvidoria da Aneel não tem atribuição de promover uma "auditoria interna" da agência, atuando apenas como auditora do atendimento às solicitações. Dessa forma, sua importância para a transparência fica muito comprometida, embora ainda tenha um papel relevante para o controle social da agência.

Apesar dessas ressalvas, como avaliação final podemos considerar o nível de transparência da Aneel bastante satisfatório, e significativamente superior ao do Ministério das Minas e Energia (MME). Interessante notar que Gelis Filho (2004), em trabalho recente em que verificou se as entidades reguladoras atuais diferem em seu desenho institucional quanto à independência e transparência, indicou a Aneel como a agência com maior grau de transparência, mesmo adotando parâmetros diferentes para avaliação da transparência, a saber: a existência de contrato de gestão, decisão colegiada, consulta pública e ouvidoria.

Finalmente, mesmo supondo que os problemas de legitimidade decorrentes da atividade regulatória e a complexidade do setor, discutidos por Salgado (2003), possam ter influenciado positivamente a Aneel em busca de maior transparência, a pesquisa não encontrou dados empíricos que apóiem essa afirmação. Estudos mais aprofundados poderiam explicar melhor essa questão, principalmente quando lembramos que do ponto de vista da legislação de criação e regulamentação da Aneel, a obrigação de ser transparente está definida de forma muito vaga, dando margem à existência de um menor grau de transparência por parte da agência, sem que isso pudesse ser contestado pelo governo ou mesmo pela sociedade em geral. 
Aqências Requladoras e Transparência: a Disponibilização de Informações pela Aneel

\section{Referências bibliográficas}

ABRANCHES, S. Reforma regulatória: conceitos, experiências e recomendações. Revista do Serviço Público, v. 50, n. 2, p. 19-49, abr./jun. 1999.

ABRUCIO, F. L. Os avanços e os dilemas do modelo pós-burocrático: a reforma da administração pública à luz da experiência internacional recente. In: PEREIRA, L. C. B.; SPINK, P. (Orgs.). Reforma do Estado e administração pública gerencial. Rio de Janeiro: FGV, 1998. cap. 7, p. 173-99.

; LOUREIRO, M. R. G. (Orgs.). O Estado numa era de reformas: os anos FHC. Brasília: MP/Seges, 2002a. Disponível em: <www.gestaopublica.gov.br/>. Acesso em: 12 nov. 2003.

BRASIL. Presidência da República. Plano diretor da reforma do aparelho do Estado. Brasília: Presidência da República, 1995.

Lei n. 9.755, de 16 de dezembro de 1998. Dispõe sobre a criação de home page na Internet, pelo Tribunal de Contas da União, para divulgação dos dados e informações que especifica, e dá outras providências. Disponível em: <www.contaspúblicas.gov.br>. Acesso em: 7 set. 2004.

Instrução Normativa n. 28, de 5 de maio de 1999. Estabelece regras para a implementação da home page Contas Públicas, de que trata a Lei n. 9.755/98. 1999. Disponível em: <contaspublicas.gov.br/TCU_InstrNorm28-99.htm>. Acesso em: 7 set. 2004.

Presidência da República. Comitê Executivo do Governo Eletrônico. 2 anos de governo eletrônico: balanço de realizações e desafios futuros. Brasília, 2002. Disponível em: <www.governoeletronico.gov.br/arquivos/Balanco_2_Anos_Egov.pdf>. Acesso em: 26 abr. 2003.

Casa Civil. Análise e avaliação do papel das agências reguladoras no atual arranjo institucional brasileiro. Relatório do Grupo de Trabalho Interministerial. 2003.

CLAD (CENTRO LATIONAMERICANO DE ADMINISTRACIÓN PARA EL DESARROLLO). La responsabilización en la nueva gestión pública latinoamericana. Buenos Aires e Caracas: Clad/BID/Eudeba, 2001.

COSTA, V. M. F. A dinâmica institucional da reforma do Estado: um balanço do período FHC. In: ABRUCIO, F.; LOUREIRO, M. R. (Orgs.). O Estado numa era de reformas: os anos FHC. Brasília: Seges/MP, 2002.

GELIS FILHO, A. Análise do desenho normativo de instituições reguladoras do presente e do passado. In: ENCONTRO DE ADMINISTRAÇÃO PÚBLICA E GOVERNANÇA — EnAPGANPAD, 1., Rio de Janeiro, 2004. Anais... Rio de Janeiro: Anpad, 2004. 
MAJONE, G. The new European agencies: regulation by information. Journal of European Public Policy, v. 4, n. 2, p. 262-275, 1997.

. Do Estado positivo ao Estado regulador: causas e conseqüências de mudanças no modo de governança. Revista do Serviço Público, v. 50, n. 1, p. 5-36, 1999.

MELO, M. A. B. C. A política da ação regulatória: responsabilização, credibilidade e delegação. Revista Brasileira de Ciências Sociais, v. 116, n. 46, p. 55-68, 2001.

As agências regulatórias: gênese, desenho institucional e governança. In: ABRUCIO, F.; LOUREIRO, M. R. (Orgs.). O Estado numa era de reformas: os anos FHC. Brasília: Seges/MP, 2002. p. 247-305.

O'DONNELL, G. Accountability horizontal e as novas poliarquias. Revista Lua Nova, São Paulo, n. 44, p. 27-52, 1998.

OECD (ORGANISATION FOR ECONOMIC CO-OPERATION AND DEVELOPMENT). Glossary of key terms in evaluation and results based management. Paris, 2002. Disponível em: <www.oecd.org/dac/evaluation>. Acesso em: 12 nov. 2003.

PACHECO, R. S. Agências reguladoras na infra-estrutura e na área social no Brasil: gênese e indistinções. In: ENCONTRO ANUAL DA ANPOCS, 28., Caxambu, 2004. Anais... Caxambu: Anpocs, 2004.

PIRES, J. C. L.; GOLDSTEIN, A. Agências reguladoras brasileiras: avaliação e desafios. Revista do BNDES, Rio de Janeiro, v. 8, n. 16, dez. 2001. Disponível em: <www.bndes. gov.br/conhecimento/revista/rev1601.pdf>. Acesso em: 16 jun. 2005.

PÓ, M. V.; ABRUCIO, F. L. Gênese e indefinições da accountability nas agências reguladoras brasileiras: o caso da Anatel e da ANS. In: ENCONTRO ANUAL DA ANPAD, 28., Curitiba, 2004. Anais... Curitiba: Anpad, 2004.

PRZEWORSKI, A.; STOKES, S. C.; MANIN, B. (Orgs.). Democracy, accountability and representation. New York: Cambridge University Press, 1999.

REZENDE, F. A. Reforma do Estado em perspectiva comparada. In: NASSUNO, M.; KAMADA, P. (Orgs.). Balanço da reforma do Estado no Brasil: a nova gestão pública. Brasília: Seges, 2002.

SALGADO, L. H. Agências reguladoras na experiência brasileira: um panorama do atual desenho institucional. Brasília: Ipea, 2003. (Texto para Discussão, n. 941).

SARTORI, G. Homo videns: televisão e pós-pensamento. Bauru: Edusc, 2001.

SPECK, B. W. (Org.). Caminhos da transparência. Campinas: Unicamp, 2002.

STARK, D.; BRUSZT, L. Enabling constraints: fontes institucionais de coerência nas políticas públicas no pós-socialismo. Revista Brasileira de Ciências Sociais, n. 36, fev. 1998.

Rap Rio de Janeiro 40(4):631-46, Jul./Ago. 2006 